\title{
Work Posture Evaluation on Ergonomic "Colet" Workbench Design in Batik Coloring Process using Nordic Body Map and Rapid Entire Body Assessment
}

\section{Evaluasi Postur Kerja pada Rancang Bangun Rangka Meja Colet Batik Ergonomis menggunakan Nordic Body Map dan Rapid Entire Body Assessment}

\author{
Amalia $^{1 *}$, Rudy Tjahyono ${ }^{1}$, Jazuli $^{1}$, Rodia Syamwil $^{2}$ \\ ${ }^{1}$ Program Studi Teknik Industri, Universitas Dian Nuswantoro \\ Jl. Nakula I No. 5-11 Semarang, 50131 \\ 2 Jurusan Teknologi Jasa dan Produksi, Universitas Negeri Semarang \\ Sekaran, Kec. Gunung Pati Semarang, 50229 \\ email : amalia@dsn.dinus.ac.id \\ doi: https://doi.org/10.31315/opsi.v14i2.5302
}

Received: $26^{\text {th }}$ July 2021; Revised: 15 th August 2021; Accepted: 20 ${ }^{\text {th }}$ August 2021;

Available online: $21^{\text {st }}$ December 2021; Published regularly: December 2021

\begin{abstract}
The effort to preserve batik is to maintain the continuity of batik production. Coloring process is one of the important processes in batik production. In addition to the dyeing technique, there is a "colet" technique in batik coloring process. Colet technique is considered an efficient technique in saving coloring dyes. The "colet" process is still carried out without standards and does not consider ergonomic aspects. This study aims to analyze the risk level of batik workers posture in "colet" technique coloring process. This research is an observational study with data analysis using the Nordic Body Map (NBM) and Rapid Entire Body Assessment (REBA). The measurement of NBM got a score of 35 with body complaints on back, shoulder, arm, and knees, then decreased to NBM Score of 29 after the implementation of workbench. Based on the measurement, the risk level with the initial work posture has a score 9 and 7, which means the posture needs immediate corrective action to prevent occupational diseases. The implementation of Ergonomic "Colet" workbench is a way to improve work posture so the risk could be decreased, with score 4 both in standing and sitting working position.
\end{abstract}

Keywords: Colet technique, work posture, NBM, REBA

\begin{abstract}
ABSTRAK
Upaya pelestarian batik adalah dengan menjaga kontinuitas produksi batik. Salah satu proses penting dalam pembuatan batik adalah proses pewarnaan. Teknik colet merupakan salah satu teknik pewarnaan yang efisien dalam penghematan zat warna. Proses pencoletan masih dilakukan seadanya tanpa standar dan tidak mempertimbangkan aspek ergonomis. Penelitian ini bertujuan untuk menganalisis tingkat resiko dari postur pekerja batik pada bagian proses pencoletan. Penelitian bersifat observasional dengan analisis data menggunakan metode Nordic Body Map (NBM) dan Rapid Entire Body Assessment (REBA). Pengukuran keluhan mendapatkan skor 35 pada pekerjaan colet dengan keluhan pada punggung, bahu, lengan, dan lutut, kemudian menurun menjadi skor 29 setelah implementasi meja. Berdasarkan pengukuran, tingkat resiko dengan postur kerja awal memiliki skor 9 dan 7, yang artinya perlu tindakan perbaikan segera untuk mencegah penyakit akibat kerja. Perbaikan postur kerja dengan implementasi meja colet ergonomi, diperoleh skor 4 baik untuk posisi kerja berdiri dan duduk.
\end{abstract}

Kata Kunci: Pencoletan, postur kerja, NBM, REBA 


\section{PENDAHULUAN}

Batik sebagai warisan budaya non bendawi milik bangsa Indonesia yang memiliki daya ungkit besar terhadap penciptaan nilai tambah dan perdagangan, harus dilestarikan. Upaya pelestarian dapat dilakukan antara lain dengan menjaga kontinuitas produksi batik. Proses produksi batik tradisional terdiri dari beberapa tahapan, dan salah satu proses penting yaitu pewarnaan. Proses pewarnaan batik dapat dilakukan dengan cara pencelupan dan pencoletan. Proses pencoletan merupakan pekerjaan pemberian warna-warna pada bidangbidang tertentu pada kain batik dengan menggunakan kuas. Menurut Lestari (2018), teknik pewarnaan colet merupakan teknik yang praktis dan efisien dalam penghematan zat warna bila dibandingkan dengan teknik celup.

Proses pencoletan di beberapa UMKM, saat ini dilakukan seadanya oleh para pekerja batik atau pengrajin batik. Ada yang menggunakan alas koran atau goni yang dibentangkan di atas lantai atau tanah. Ada yang menggunakan meja kayu dengan alas goni, ada pula yang menggunakan rangka yang ditumpangkan di atas bangku. Secara keseluruhan dapat dikatakan bahwa proses pencoletan dilakukan tanpa standar, dan tidak mempertimbangkan aspek ergonomis dan kepraktisan kerja.

Menurut Siswiyanti dan Luthfianto (2016), sikap tubuh pembatik untuk pewarnaan colet dalam keadaan statis (diam) dalam kurun waktu 3 jam per 1 kali pewarnaan. Berdasarkan hasil wawancara dan observasi, lama pembatik melakukan proses pewarnaan colet bervariasi disesuaikan dengan luas bidang pewarnaan. Apabila suatu pekerjaan dengan sikap statis dalam jangka waktu yang lama, hal ini dapat menyebabkan kelelahan pada beban otot statis.

Menurut Lindawati dan Mulyono (2018) stasiun kerja yang tidak ergonomis dan postur kerja dapat mempengaruhi aktivitas dan produktivitas yang dapat memberikan dampak negatif. Stasiun kerja yang tidak ergonomis dan sikap kerja duduk dapat menyebabkan keluhan sistem musculoskeletal dan kelelahan dirasakan oleh pengrajin batik (Aliafari dkk, 2018; Lindawati \& Mulyono, 2018; Siswiyanti \& Saufik, 2011).

Berdasarkan hasil pengukuran menggunakan Nordic Body Map (NBM) pada postur kerja pencoletan, terdapat beberapa bagian tubuh yang memiliki keluhan. Keluhan "sakit" dengan total $189 \%$, yang diurutkan dari tertinggi hingga terendah yaitu pada bagian punggung (67\%), bahu kanan (44\%), lengan atas kanan (33\%), tangan kanan (11\%), lutut kiri (11\%), dan lutut kanan (11\%).

Penelitian ini bertujuan untuk mengidentifikasi tingkat keluhan pada bagian tubuh pekerja batik pada proses pewarnaan dengan teknik colet menggunakan Nordic Body Map (NBM), dan menganalisis tingkat resiko postur pekerja saat ini dengan metode Rapid Entire Body Assessment (REBA), sebelum dan setelah menggunakan meja colet.

\section{METODE}

Penelitian dilakukan menggunakan metode survey dan observasional di UMKM RK De Suket. Pengukuran keluhan dengan menyebarkan kuesioner NBM sebagai pengukuran tingkatan resiko keluhan. NBM merupakan metode pengukuran subyektif untuk mengukur keluhan rasa sakit atau ketidaknyamanan dalam tubuh, dan mengidentifikasi penyakit sistem gerak / musculoskeletal (Azwar, 2020; Dewi, 2020; Setyanto dkk, 2015; Soesilo Novi, 2018; Pratama, 2017; Wakhid, 2014).

Aktivitas pekerja pewarnaan colet direkam, kemudian dilakukan pengukuran. Pengukuran sudut tubuh menggunakan software Kinovea. Metode analisis data yang digunakan adalah metode REBA dengan REBA Assessment worksheet. REBA adalah metode efektif untuk menilai postur tubuh pekerja yaitu leher, punggung, lengan, pergelangan tangan, dan kaki (Anthony, 2020; Gorde \& Borade, 2019; Hignett, 2000; Saleh, 2017; Soesilo Novi, 2018; Thamrin, 2021)

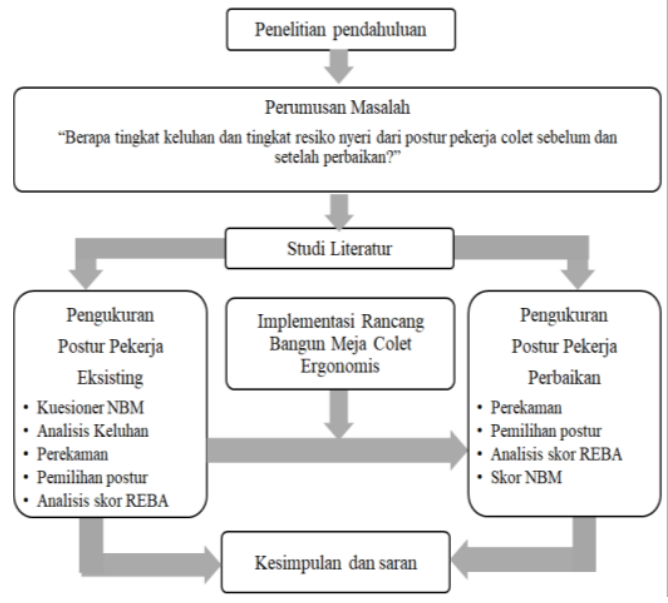

Gambar 1. Alur Metodologi 
Pengamatan dilakukan pada dua kondisi, yaitu pada kondisi eksisting pekerja, dan pada kondisi setelah dilakukan pengadaan fasilitas alat bantu kerja yaitu meja colet batik hasil perancangan meja ergonomis.

\section{HASIL DAN PEMBAHASAN}

\subsection{Pengukuran Postur Kerja Awal}

\subsubsection{Pengukuran Keluhan Nyeri Postur Awal}

\section{Pencoletan}

Perilaku tidak ergonomis dapat menyebabkan keluhan ergonomic disorders. Penilaian skor NBM memiliki 28 titik tubuh terhadap individu menggunakan skala likert yang telah ditetapkan, yaitu Tidak Sakit / tidak merasakan gangguan pada bagian tertentu dengan skor 1; Agak Sakit / merasakan sedikit gangguan pada bagian tertentu dengan skor 2; Sakit / merasakan ketidaknyamanan pada bagian tubuh tertentu dengan skor 3; dan Sangat Sakit / merasakan ketidaknyamanan pada bagian tertentu dengan skala yang tinggi dengan nilai skor 4 (Aryanti, \& Arifin, 2019; Wijaya, 2019; Pratama, 2017)

Berdasarkan

hasil kuesioner, secara keseluruhan, rerata hasil skoring individu berada pada rentang resiko rendah, dengan nilai 35 . Hasil kuesioner dapat dipengaruhi pula lama kerja pekerja colet.
Ditinjau lebih detil, terdapat beberapa keluhan yang terasa sakit (189\%) dan agak sakit (256\%) pada beberapa bagian tubuh. Keluhan "sakit" yang diurutkan dari tertinggi hingga terendah yaitu pada bagian punggung (67\%), bahu kanan (44\%), lengan atas kanan (33\%), tangan kanan (11\%), lutut kiri (11\%), dan lutut kanan (11\%). Keluhan "agak sakit" pada tubuh leher bagian bawah (33\%), tangan kanan (33\%), lutut kiri $(33 \%)$, bahu kanan (22\%), pinggang (22\%), lengan bawah kanan (22\%), dan lutut kanan $(22 \%)$. Hasil pengukuran NBM dapat dilihat pada Gambar 2 dan Gambar 3.

Berdasarkan hasil pengukuran keluhan bagian tubuh, dilakukan identifikasi penyebab keluhan pekerja, yang ditampilkan pada Tabel 1 .

Tabel 1. Keluhan Bagian Tubuh dan Penyebab

\begin{tabular}{|c|c|c|}
\hline No & Bagian Tubuh & Penyebab \\
\hline 1 & Punggung & $\begin{array}{l}\text { Posisi punggung yang } \\
\text { membungkuk karena posisi } \\
\text { kerja dalam waktu yang } \\
\text { lama }\end{array}$ \\
\hline 2 & Bahu & $\begin{array}{l}\text { Bahu terangkat saat } \\
\text { melakukan pencoletan serta } \\
\text { dalam posisi statis dalam } \\
\text { waktu yang cukup lama }\end{array}$ \\
\hline 3 & Lengan & $\begin{array}{l}\text { Lengan atas dalam posisi } \\
\text { statis dan terangkat }\end{array}$ \\
\hline 4 & Lutut & $\begin{array}{l}\text { Lutut ditekuk pada posisi } \\
\text { jongkok (squatting) ketika } \\
\text { melakukan pencoletan }\end{array}$ \\
\hline
\end{tabular}

\subsubsection{Penilaian Skor REBA Postur Kerja Awal}

Proses pencoletan menggunakan fasilitas terbatas yaitu pada posisi jongkok (squatting posture) di lantai dengan alas kerja karung goni, atau karpet (Gambar 4). Pengukuran postur kerja dilakukan untuk mengukur tingkat resiko pada posisi kerja awal guna mengetahui resiko dan tindakan yang diperlukan, dapat dilihat pada Tabel 2.

Tabel 2. Squatting Posture pada Pekerja Colet 1 (di Lantai)

\begin{tabular}{|c|c|c|c|}
\hline \multicolumn{2}{|c|}{ Body Part Analysis } & Score & Total Score \\
\hline Trunk & $55^{\circ}$ & $3+1$ & \multirow{9}{*}{$\begin{aligned} \text { REBA Score } & =9 \\
\text { Risk } & =\text { High } \\
\text { Action } & =\text { Necessary Soon }\end{aligned}$} \\
\hline Neck & $6^{\circ}$ & 1 & \\
\hline Leg & $36^{\circ}$ & $1+2$ & \\
\hline Upper Arm & $110^{\circ}$ & 4 & \\
\hline Lower Arm & $5^{\circ}$ & 1 & \\
\hline Wrist & $36^{\circ}$ & 2 & \\
\hline Force & $<5 \mathrm{~kg}$ & 0 & \\
\hline Couple & Good & 0 & \\
\hline Activity & Body parts are static & 1 & \\
\hline
\end{tabular}




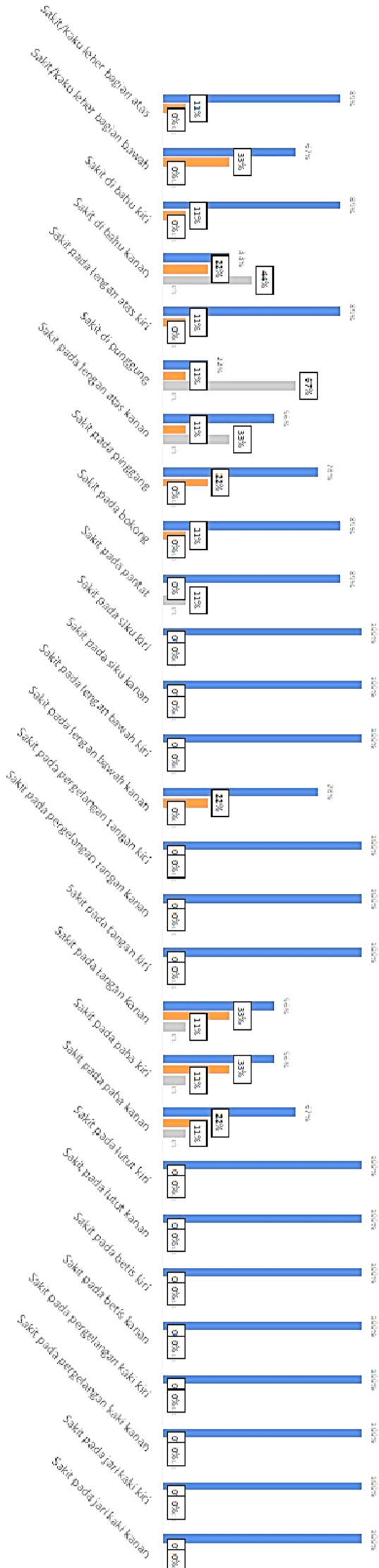

Gambar 3. NBM Postur Pencoletan Awal (Posisi Kerja di Lantai)

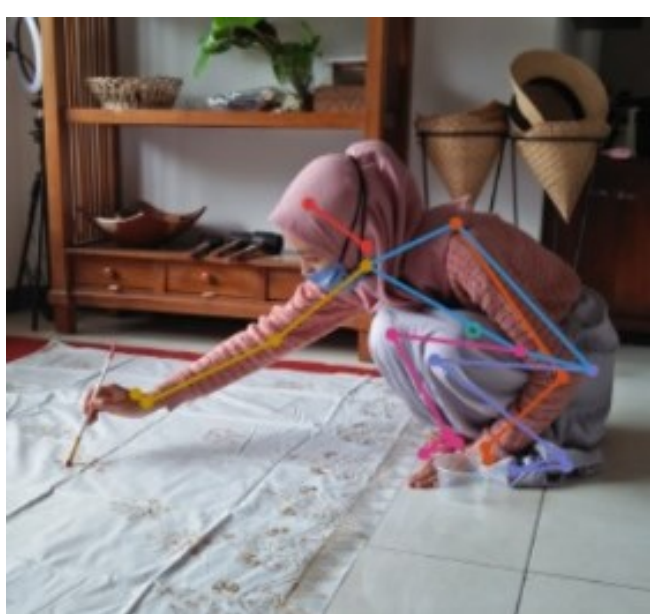

(a)

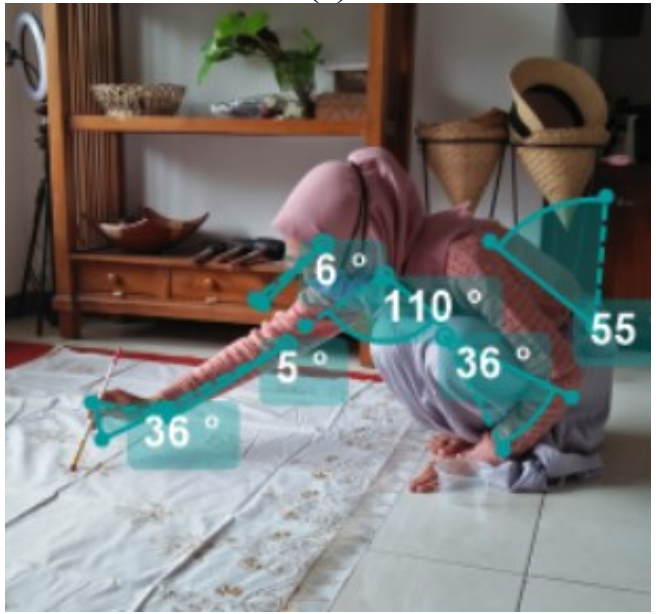

(b)

Gambar 4. (a) Aktivitas Eksisting Pencoletan (Squat) tanpa sudut, dan (b) dengan sudut

Berdasarkan pengukuran sudut terhadap aktivitas colet diperoleh hasil pemberian skor pada tabel grup A (punggung / trunk, leher / neck, dan kaki / leg), grup B dan grup C (hasil rekap grup A dan B). Posisi punggung dengan sudut $55^{\circ}$ flexion sehingga termasuk dalam pergerakan $>60^{\circ}$ dengan skor 3 , dengan penambahan skor 1 pada sisi punggung. Posisi leher $6^{\circ}$ termasuk dalam $<20^{\circ}$ dengan skor 1 . Posisi kaki adalah jongkok dengan bobot tubuh tersebar merata, dengan lutut menekuk $>60^{\circ}$ yaitu membentuk $36^{\circ}$ sehingga diberi skor $1+2=3$. Hasil pada tabel REBA skor Grup A sebesar 6, yang berarti perlu adanya tindakan untuk memberikan alternatif dalam mengatasi postur kerja yang kurang ergonomis.

Pada perhitungan Grup B terdiri dari lengan atas (upper arm), lengan bawah (lower arm) dan pergelangan tangan (wrist). Posisi lengan atas bagian kanan membentuk sudut pergerakan 
Tabel 3. Awkward Posture pada Pekerja Colet 2 (di Lantai)

\begin{tabular}{|c|c|c|c|}
\hline \multicolumn{2}{|c|}{ Body Part Analysis } & Score & \multirow{5}{*}{ 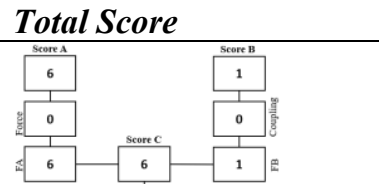 } \\
\hline Trunk & $95^{\circ}$ & 4 & \\
\hline Neck & $4^{\circ}$ & 1 & \\
\hline Leg & $22^{\circ}$ & $1+2$ & \\
\hline Upper Arm & $89^{\circ}$ & $3-1$ & \\
\hline Lower Arm & $4^{\circ}$ & 1 & \multirow{3}{*}{ REBA Score $=7$} \\
\hline Wrist & $9^{\circ}$ & 1 & \\
\hline Force & $<5 \mathrm{~kg}$ & 0 & \\
\hline Couple & Good & 0 & \multirow{2}{*}{$\begin{array}{ll}\text { Risk } & =\text { Medium } \\
\text { Action } & =\text { Necessary }\end{array}$} \\
\hline Activity & Body parts are static & 1 & \\
\hline
\end{tabular}

tangan atas ke depan terhadap sumbu tubuh sebesar $110^{\circ}$ sehingga pergerakan termasuk $>$ $90^{\circ}$ dan memiliki skor 4 . Posisi lengan bawah bagian kanan dengan pergerakan ke depan membentuk sudut $5^{\circ}$ dengan skor 1 . Sudut pergelangan tangan adalah $36^{\circ}$ dengan termasuk dalam range $>15^{\circ}$ dengan skor 2 . Berdasarkan sudut pergerakan tubuh lengan dan pergelangan tangan, skor Grup B pada Tabel REBA yaitu 5. Pada grup B ditambah skor coupling 0 dimana pegangan pada aktivitas ini memiliki kekuatan pegangan yang baik yaitu masuk kategori "good".

Berdasarkan nilai skor grup A (skor 6) dan B (skor 5), maka diperoleh nilai skor Grup C yaitu 8. Pada saat melakukan aktivitas, posisi tubuh bertahan lebih dari 1 menit dalam posisi statis, sehingga Skor C ditambah dengan skor aktivitas $(+1)$ menjadi skor REBA sebesar 9 .

Berdasarkan pengukuran awal postur pekerja dari leher, punggung, lengan, pergelangan tangan, hingga kaki, diperoleh nilai skor REBA sebesar 9, termasuk dalam skala level resiko tinggi, yang berarti apabila postur kerja tidak segera diperbaiki dapat menimbulkan penyakit akibat kerja musculoskeletal disorder (MSDs) pada otot, tendon, ataupun syaraf yang dapat merugikan pekerja maupun perusahaan. Didukung oleh beberapa penelitian (Anthony, 2020, Wajdi \& Kusmasari, 2015) bahwa otot yang menerima beban statis secara berulang dan dalam waktu lama dapat menyebabkan keluhan rasa nyeri di beberapa segemen tubuh akibat kerusakan pada sendi, ligamen, dan tendon.

Berdasarkan observasi, postur kerja di lantai cukup beragam. Dilakukan pula, pengukuran REBA pada postur pencoletan dengan postur kerja berbeda. Gambar 5 merupakan postur canggung (awkward posture) pada pekerja.

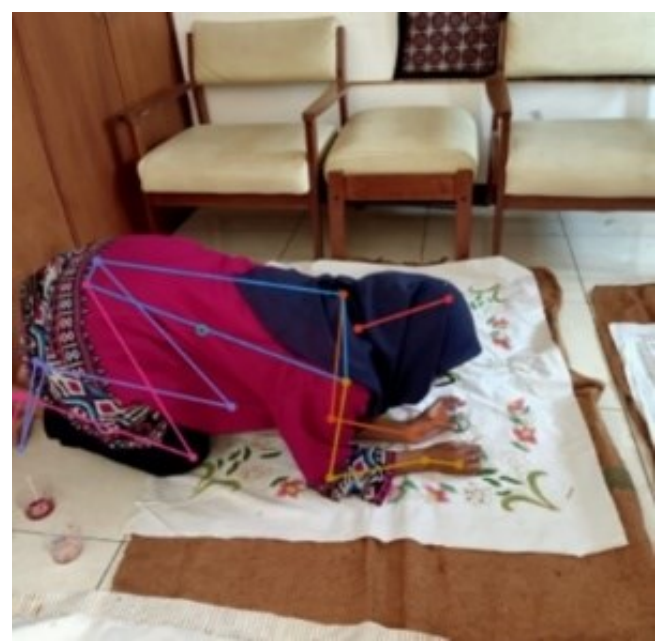

(a)

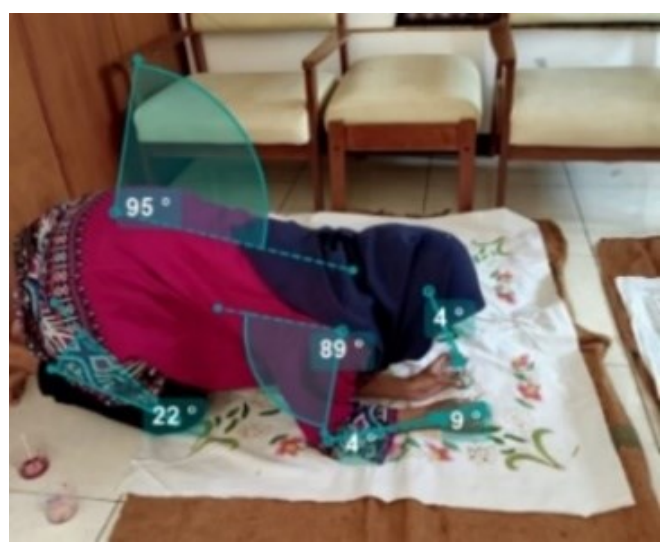

(b)

Gambar 5. (a) Awkward Posture pada Aktivitas Eksisting Pencoletan tanpa sudut, dan (b) dengan sudut

Berdasarkan pengukuran sudut, posisi punggung (trunk) dengan sudut $95^{\circ}$ flexion mendapat skor 4. Posisi leher (neck) membentuk sudut $4^{\circ}$ dengan skor 1 . Posisi kaki dengan lutut bertumpu di lantai sehingga bobot tubuh tersebar merata, dengan lutut menekuk dengan sudut $22^{\circ}$ sehingga diberi skor $1+2=3$. Hasil pada tabel REBA skor Grup A sebesar 6, sehingga perlu 
adanya tindakan untuk mengatasi postur kerja yang kurang ergonomis. Posisi lengan atas (upper arm) bagian kanan membentuk sudut $89^{\circ}$, tetapi lengan bersandar di lantai, postur lengan dibantu gravitasi, sehingga skornya 3$1=2$. Posisi lengan bawah (lower arm) bagian kanan dengan pergerakan ke depan membentuk sudut $4^{\circ}$ dengan skor 1 . Sudut pergelangan tangan (wrist) adalah $9^{\circ}$ dengan termasuk dalam range $>10^{\circ}$ dengan skor 1 . Berdasarkan sudut pergerakan tubuh lengan dan pergelangan tangan, skor Grup B pada Tabel REBA yaitu 1. Aktivitas ini memiliki kekuatan pegangan baik dengan skor coupling 0. Berdasarkan skor A dan B, maka skor C sebesar 6. Skor C ditambah dengan skor aktivitas $(+1)$ menjadi skor REBA sebesar 7, yang artinya memiliki tingkat resiko medium terhadap gangguan MSDs.

\subsection{Rancang Bangun Meja Colet dengan Pertimbangan Ergonomis sebagai Alternatif Perbaikan}

Rekayasa meja dirancang untuk meningkatkan kinerja karyawan, salah satunya adalah alat bantu ergonomis untuk menurunkan resiko cidera. Berdasarkan nilai skor postur kerja kondisi eksisting pekerja colet, dilakukan pembuatan meja kerja colet yang ergonomis, dengan perancangan berbasis antropometri, dan pengaturan posisi kerja. Menurut Sari dkk (2013) dalam Dewi Anjani dkk (2021), dan perancangan meja yang ergonomis dapat meningkatkan kenyamanan. Penerapan antropometri ukuran tubuh manusia dalam merancang sebuah fasilitas kerja dapat berpengaruh pada perubahan posisi kerja serta kenyaman (Kristanto \& Saputra, 2011; Dewi Anjani dkk, 2020).
Tabel 4. Pertimbangan Ergonomis dalam Rancangan Meja

\begin{tabular}{|c|c|c|}
\hline No & $\begin{array}{l}\text { Dimensi Meja } \\
\text { Colet }\end{array}$ & $\begin{array}{l}\text { Pertimbangan } \\
\text { Ukuran }\end{array}$ \\
\hline 1 & Tinggi meja & $\begin{array}{l}\text { Antropometri tinggi siku } \\
\text { berdiri dan tinggi bahu } \\
\text { duduk pekerja, p-50 wanita, } \\
\text { serta acuan jenis pekerjaan } \\
\text { kategori ringan. }\end{array}$ \\
\hline 2 & Lebar meja & $\begin{array}{l}\text { Ukuran lebar kain batik, dan } \\
\text { jangkauan panjang tangan } \\
\text { pekerja }\end{array}$ \\
\hline 3 & Panjang meja & $\begin{array}{l}\text { Ukuran panjang kain batik } \\
\text { yang digunakan }\end{array}$ \\
\hline
\end{tabular}

Meja colet dirancang dengan menggabungkan konsep frame rangka dengan meja. Meja yang digunakan secara umum yakni meja diberi dasar goni yang dapat meresap warna, dimana warna tersebut dapat pindah kembali ke kain apabila tidak kering. Sedangkan frame colet yang tersedia secara umum hanya berupa rangka tanpa penyangga. Ukuran meja colet menggunakan pertimbangan antropometri dan material kain yang digunakan. Rancangan perbaikan kerja dengan menggunakan postur duduk-berdiri.

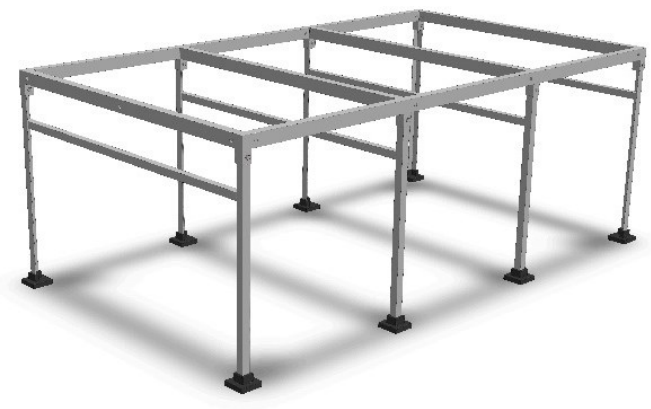

Gambar 6. Rancangan Meja Frame untuk Pekerjaan Colet dengan Rekomendasi Postur Duduk-Berdiri

Tabel 5. Implementasi Meja Frame Colet Posisi Kerja Berdiri (Standing)

\begin{tabular}{|c|c|c|c|}
\hline \multicolumn{2}{|c|}{ Body Part Analysis } & Score & \multirow{5}{*}{ 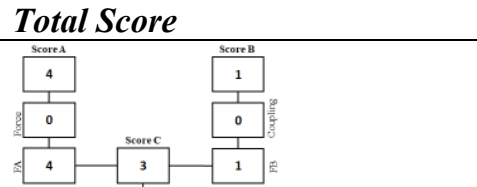 } \\
\hline Trunk & $10^{\circ}$ & $2+1$ & \\
\hline Neck & $40^{\circ}$ & 2 & \\
\hline Leg & $2^{\circ}$ & 1 & \\
\hline Upper Arm & $0^{\circ}$ & 1 & \\
\hline Lower Arm & $81^{\circ}$ & 1 & \multirow{3}{*}{ REBA Score $=3$} \\
\hline Wrist & $13^{\circ}$ & 1 & \\
\hline Force & $<5 \mathrm{~kg}$ & 0 & \\
\hline Couple & Good & 0 & Risk $\quad=$ Low \\
\hline Activity & - & 0 & $=$ Maybe Necessary \\
\hline
\end{tabular}


Tabel 6. Implementasi Meja Frame Colet Posisi Kerja Duduk (Sitting)

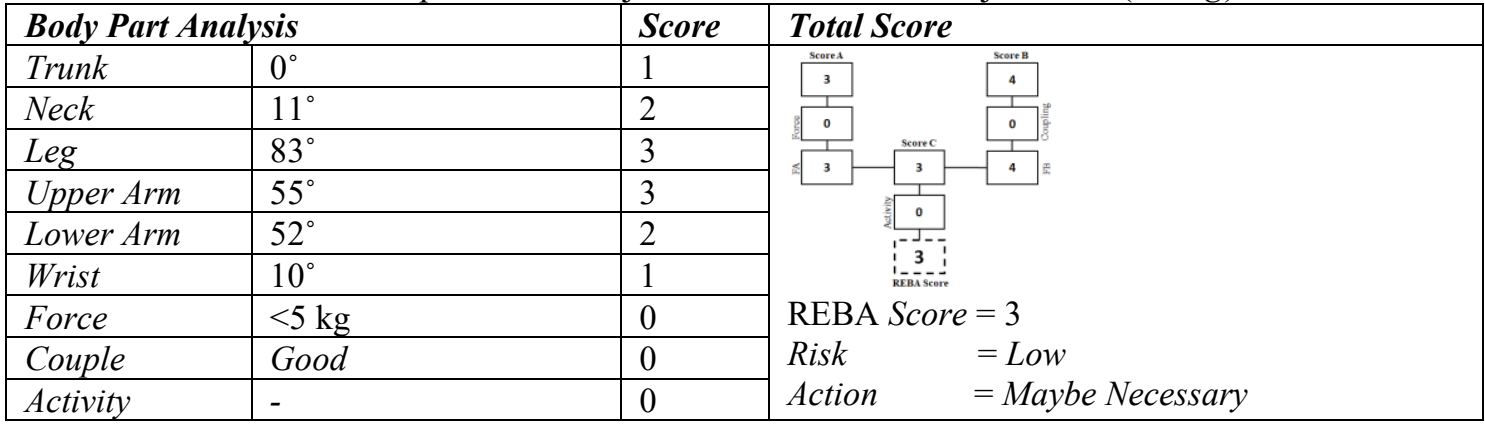

\subsection{Perbaikan Postur Kerja dengan Implementasi Meja Colet}

Postur tubuh merupakan titik penentu dalam analisa efektifitas suatu pekerjaan, dimana postur tubuh yang baik dan ergonomis dapat meningkatkan produktivitas dan output yang baik. Melalui implementasi rancang bangun meja colet, maka diharapkan posisi kerja diatur dan diperbaiki agar dapat meningkatkan kenyamanan pekerja khususnya pada bagian proses pencoletan dan menurunkan tingkat resiko keluhan bagian tubuh.

\subsubsection{Perbaikan Postur Kerja Berdiri}

Rancang bangun meja dibuat untuk posisi berdiri-duduk. Hasil pengukuran postur kerja berdiri (standing) ditampilkan pada Tabel 5.

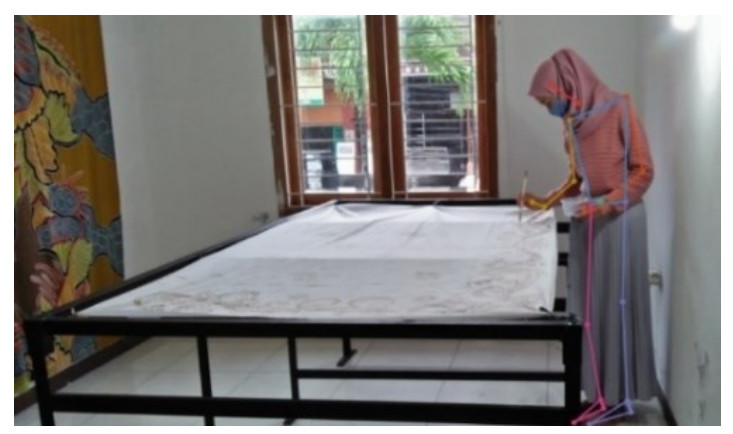

(a)

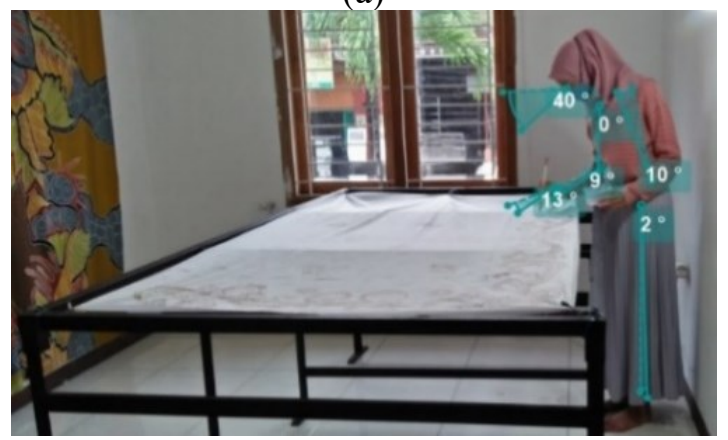

(b)

Gambar 7. (a) Postur berdiri (standing) pencoletan dengan meja tanpa sudut, dan (b) dengan sudut
Berdasarkan Tabel 4, dengan menggunakan meja frame colet yang dirancang, potensi risiko rendah dengan nilai skor REBA sebesar 3 . Tampak adanya pengurangan sudut punggung, tidak terlalu membungkuk dengan sudut $10^{\circ}$ flexion. Posisi leher membentuk sudut $40^{\circ}$ dimana pekerja sedikit menunduk untuk dapat memastikan ketepatan pewarnaan pada bagian yang dicolet. Posisi kaki juga tegak dan lutut tidak menekuk sehingga nilai skor 1. Skor Grup A pada posisi berdiri (standing) sebesar 4 .

Pada posisi berdiri, baik lengan atas, lengan bawah, dan pergelangan tangan dalam kondisi yang baik dengan skor masing-masing sebesar 1 . Skor Grup B pada posisi berdiri (standing) sebesar 1. Penggabungan Grup A dan B menghasilkan skor Grup C sebesar 3 .

\subsubsection{Perbaikan Postur Kerja Duduk}

Variasi postur pada rancang bangun meja yaitu posisi duduk (sitting) dimana hasil pengukuran dapat dilihat pada Gambar 8 dan Tabel 6.

Berdasarkan pengukuran sudut pada Tabel 5, posisi duduk dengan menggunakan meja mengurangi sudut pada punggung yaitu punggung tegak pada sumbu tubuh, dan menghasilkan skor 1 . Posisi leher membentuk sudut $11^{\circ}$, jarak mata dengan kain atau area kerja pencoletan tidak begitu jauh dengan skor 2 .

Posisi kaki dan lutut tampak menekuk, tapi bobot tubuh ditopang oleh kursi sehingga aman, dengan skor 3. Skor Grup A pada posisi duduk yaitu 3.

Lengan atas membentuk sudut sebesar $55^{\circ}$ dengan posisi bahu datar atau tidak ada kenaikan pada bahu dengan skor 3. Lengan bawah membentuk sudut $52^{\circ}$ dengan skor 2 dan pergelangan tangan sudut $10^{\circ}$ dengan skor 1 . Aktivitas kekuatan pegangan baik, sehingga nilai 
skor Grup B yaitu 4. Grup C yang merupakan penggabungan Grup A dan B mendapatkan skor 3. Nilai REBA pada posisi duduk (sitting) yaitu 3. Hal ini menunjukkan bahwa pada posisi kerja ini memiliki potensi resiko rendah.

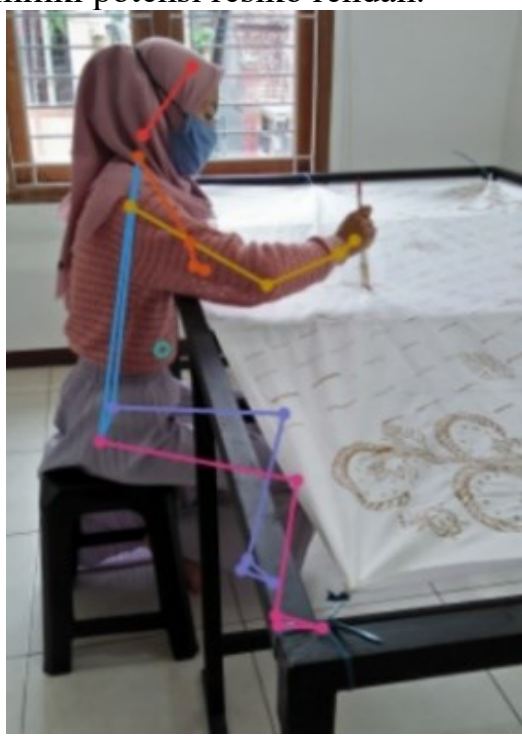

(a)
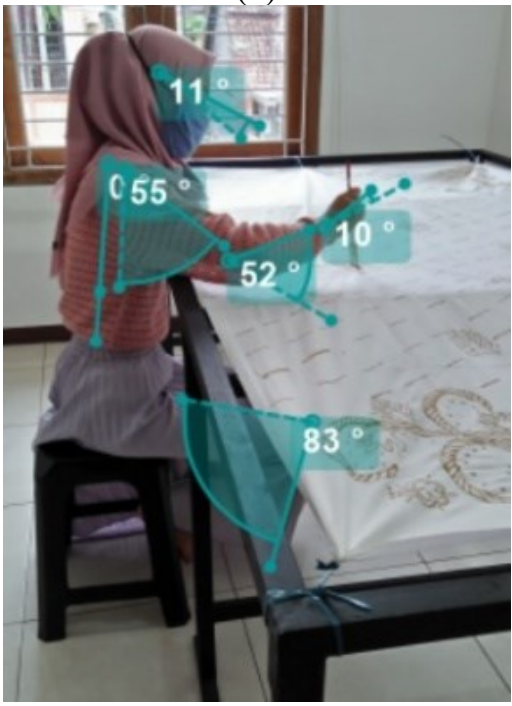

(b)

Gambar 8. (a) Postur duduk (sitting) Pencoletan dengan Meja tanpa sudut, dan (b) dengan sudut

\subsubsection{Pengukuran Keluhan Setelah Penggunaan}

\section{Meja Colet}

Berdasarkan survey yang dilakukan, nilai skor NBM menurun menjadi 29. Keluhan rasa sakit pada bahu kanan, punggung, lengan atas kanan, pantat, tangan kanan, lutut kanan dan lutut kiri menurun dari $189 \%$ menjadi $0 \%$. Keluhan rasa agak sakit juga menurun dari
$256 \%$ menjadi $167 \%$. Grafik hasil survey NBM dapat dilihat pada Gambar 9.

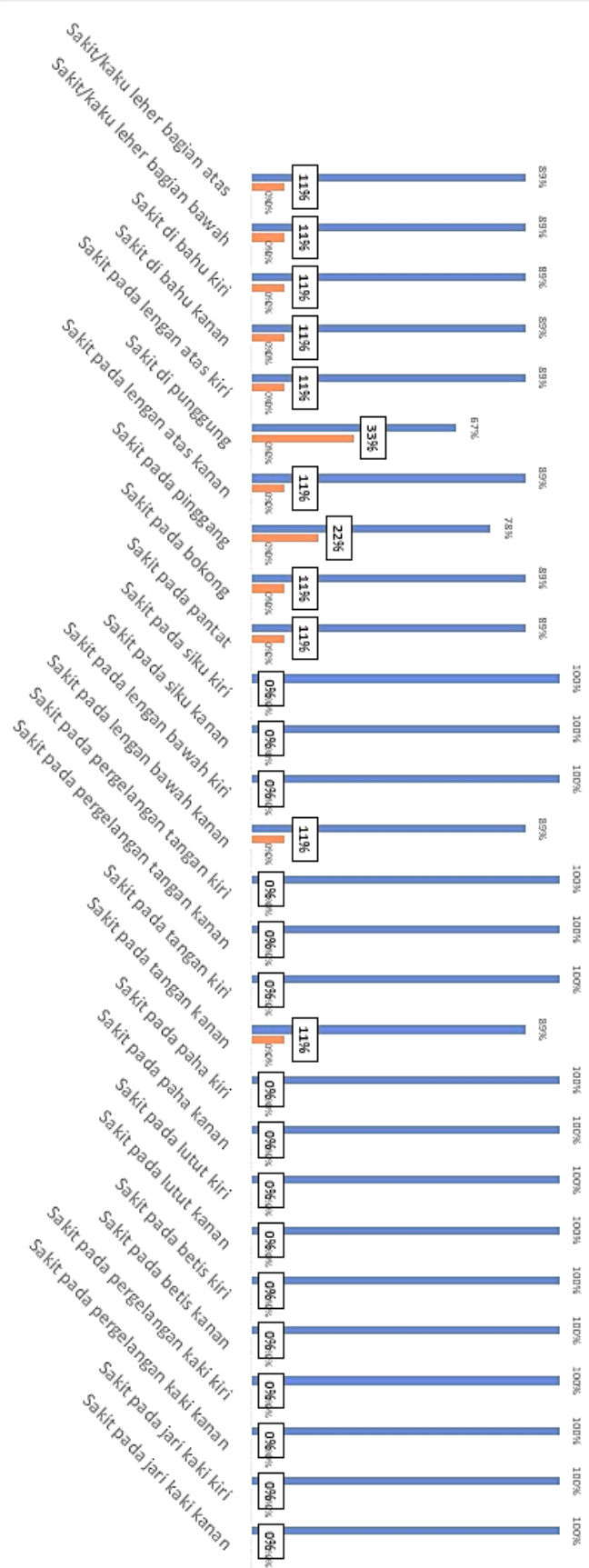

Gambar 9. NBM Postur Pencoletan Setelah Implementasi Rancang-Bangun Meja Colet

\subsection{Rangkuman Perbandingan Postur Pekerja}

Postur kerja yang tidak aman yaitu postur kerja yang selalu berdiri, jongkok, dan membungkuk dalam waktu yang lama (Anthony, 
2020). Oleh karena itu, perbaikan dirancangan dengan memberikan fasilitas meja kerja ergonomis dan penganturan posisi kerja untuk postur duduk-berdiri. Posisi duduk dapat digunakan dalam waktu yang lebih lama, diselingi dengan posisi berdiri yang dapat digunakan ketika proses pencoletan pada bagian tengah kain, sehingga jangkauan tangan lebih baik, dan pekerja memiliki tingkat resiko keluhan otot yang lebih rendah.Evaluasi perbaikan kerja berdasarkan nilai skor NBM dan REBA yang diringkas pada tabel 7 .

Tabel 7. Ringkasan Evaluasi Pekerjaan Colet Sebelum dan Setelah Perbaikan

\begin{tabular}{|c|c|c|}
\hline Kriteria & $\begin{array}{l}\text { Postur Awal } \\
\text { (di lantai) }\end{array}$ & $\begin{array}{l}\text { Perbaikan } \\
\text { Postur } \\
\text { (dengan meja) }\end{array}$ \\
\hline $\begin{array}{l}\text { Pengamatan } \\
\text { postur }\end{array}$ & $\begin{array}{l}\text { Jongkok dan } \\
\text { membungkuk }\end{array}$ & $\begin{array}{l}\text { Berdiri dan } \\
\text { duduk }\end{array}$ \\
\hline NBM Score & 35 & 29 \\
\hline REBA & 9 dan 7 & 3 dan 3 \\
\hline Score & & \\
\hline Risk Level & $\begin{array}{l}\text { Tinggi dan } \\
\text { sedang }\end{array}$ & Rendah \\
\hline Action & $\begin{array}{l}\text { Perlu perbaikan } \\
\text { segera }\end{array}$ & $\begin{array}{l}\text { Mungkin } \\
\text { diperlukan } \\
\text { perbaikan }\end{array}$ \\
\hline
\end{tabular}

\section{KESIMPULAN}

Berdasarkan pengamatan dan pengukuran REBA terjadi penurunan resiko dari tinggi dan sedang menjadi rendah dengan adanya implementasi rancang bangun meja frame colet. Begitu pula pada skor NBM, dimana keluhan pada bagian punggung, bahu, lengan, dan lutut dapat dikurangi. Dengan adanya meja frame colet, postur kerja pada proses pencoletan menjadi lebih nyaman dan aman, sehingga produktivitas meningkat dan menurunkan potensi sakit pada pekerja.

Saran yang diperlukan adalah agar UMKM terus melakukan evaluasi dan mengidentifikasi apabila terdapat keluhan pekerja, serta melakukan perbaikan berkesinambungan dalam setiap aktivitas produksi, tidak terbatas hanya pada bagian pencelupan.

\section{UCAPAN TERIMA KASIH}

Penulis mengucapkan terima kasih kepada Lembaga Penelitian dan Pengabdian kepada Masyarakat (LPPM) Universitas Dian Nuswantoro atas pendanaan pada penelitian ini melalui Skema Hibah Penelitian Terapan Perguruan Tinggi (001/A.38-04/UDN09/I/2021). Penulis juga berterima kasih kepada reviewer yang bersedia memberikan saran dan komentar guna meningkatkan kualitas isi jurnal.

\section{DAFTAR PUSTAKA}

Aliafari, N., Pertiwi, O. R., Anugerah, M. T., \& Sari, A. D. (2018). Analisis Eksposur Kerja pada Lini Produksi Batik Menggunakan Metode Workplace Ergonomic Risk Assessment. Seminar Dan Konferensi Nasional IDEC, ISSN: 2579-6429.

Alifiana, M. A., Sokhibi, Akh., \& Lusianti, D. (2021). Analisis Potensi Risiko Postur Kerja Pembatik Pada UMKM Muria Batik Kudus. Jurnal Rekayasa Sistem Industri, $\quad$ 6(2). https://doi.org/10.33884/jrsi.v6i2.3665

Anthony, M. B. (2020). Analisis Postur Pekerja Pengelasan Di CV. XYZ dengan Metode Rapid Entire Body Assessment (REBA). JATI UNIK: Jurnal Ilmiah Teknik Dan Manajemen Industri, 3(2), pp. 128-139. https://doi.org/10.30737/jatiunik.v3i2.84 $\underline{4}$

Ariyanti, S., \& Arifin, K. (2019). Perancangan Ulang Extrussion Torque Untuk Instalasi Panel Kaca dengan Pendekatan Ergonomi. Jurnal Ilmiah Teknik Industri, 7(1).

https://doi.org/10.24912/jitiuntar.v7i1.50 28

Azwar, A. G. (2020). Analisis Postur Kerja dan Beban Kerjda dengan Menggunakan Metode Nordic Body Map dan NASATLX pada Karyawan UKM Ucong Taylor Bandung. Jurnal Techno-Socio Ekonomika, 13(2), 90-101.

Dewi Anjani, R., Nugraha, A. E., Sari, R. P., \& Santoso, D. T. (2021). Perancangan Alat Bantu Kerja dengan Menggunakan Metode Antropometri dan Material Selection Pada Industri Sepatu. Jurnal Teknologi, 13(1), pp 15-24.

Dewi, N. F. (2020). Identifikasi Risiko Ergonomi dengan Metode Nordic Body. Jurnal Sosial Humaniora Terapan, 2(2), 125-134.

Gorde, M. S., \& Borade, A. B. (2019). The Ergonomic Assessment of Cycle 
Rickshaw Operators Using Rapid Upper Limb Assessment (Rula) Tool and Rapid Entire Body Assessment (Reba) Tool. System Safety: Human - Technical Facility - Environment, 1(1). https://doi.org/10.2478/czoto-2019-0028

Hamdy, M. I., \& Zalisman, S. (2018). Analisa Postur Kerja dan Perancangan Fasilitas Penjemuran Kerupuk yang Ergonomis Menggunakan Metode Analisis Rapid Entire Body Assessment (REBA) dan Antropometri. Jurnal Sains, Teknologi Dan Industri, 16(1), 57. https://doi.org/10.24014/sitekin.v16i1.53 $\underline{88}$

Hignett, S., \& McAtamney, L. (2000). Rapid Entire Body Assessment (REBA). Applied Ergonomics, 31(2), 201-205. https://doi.org/10.1016/S00036870(99)00039-3

Lindawati, L., \& Mulyono, M. (2019). Evaluasi Postur Kerja Pengrajin Batik Tulis Aleyya Batik di Yogyakarta. Journal of Public Health Research and Community Health Development, 1(2), pp. 131 - 143. https://doi.org/10.20473/jphrecode.v1i2. 16245

Pratama, P., Tannady, H., Nurprihatin, F., Ariyono, H. B., \& Sari, S. M. (2017). Identifikasi Risiko Ergonomi dengan Metode Quick Exposure Check dan Nordic Body Map. Jurnal Penelitian Dan Aplikasi Sistem Dan Teknik Industri, 11(1).

Saleh, A. R. (2017). Rancang Bangun Mesin Pengiris Ubi Kayu menggunakan Pendekatan Nordic Body Map (NBM) dan Pendekatan Antropometri. Jurnal TIN Universitas Tanjungpura, 11-15. http://jurnal.untan.ac.id/index.php/jtinU NTAN/article/view/19949

Setyanto, N. W., Efranto, R., Lukodono, R. P., \& Dirawidya, A. (2015). Ergonomics analysis in the scarfing process by owas, nios and nordic body map' s method at slab steel plant' s division. International Journal of Innovative Research in Science, Engineering and Technology, 4(3), 1086-1093.

Siswiyanti, S., \& Luthfianto, S. (2016). Perubahan Postur/Sikap Tubuh Pada Aktivitas Pewarnaan Batik (Colet) Setelah Dilakukan Perancangan Meja
Batik Secara Ergonomi Untuk Mengurangi Keluhan. Jurnal Rekayasa Sistem Industri, 5(1). https://doi.org/10.26593/jrsi.v5i1.1913.5 4-58

Siswiyanti, \& Rusnoto. (2017). Analisa Postur Kerja Pada Pewarnaan Batik Tulis (Celup Tradisional) dan (Celup Mesin) Menggunakan Metode Rapid Upper Limb Assessment (RULA). Prosiding Seminar Nasional Multi Disiplin Ilmu \& Call Of Papers Unisbank Ke-3 (sendi_u3), ISBN: 9-789-7936-499-93, pp. 263-272.

Soesilo, N., \& Alexander, Y. (2019). Perancangan Alat Bantu Perpindahan Barang yang Ergonomis (Studi Kasus di PT."X" Bandung). Journal of Integrated System, 1(2), 230-251. https://doi.org/10.28932/jis.v1i2.1104

Thamrin, Y., Pasinringi, S., Darwis, A. M., \& Putra, I. S. (2021). Relation of body mass index and work posture to musculoskeletal disorders among fishermen. Gaceta Sanitaria, 35, S79S82.

https://doi.org/10.1016/j.gaceta.2020.12. 022

Triyanto, B. (2012). Analisis Postur Kerja Menggunakan Metode RULA Dan Perancangan Ulang Stasiun Kerja Finishing Batik. Jurnal Teknik Industri, 18.

Wajdi, F., \& Kusmasari, W. (2015). Resiko jenis pekerjaan terhadap keluhan Msds pada perawat RSUD Serang Banten. Teknik Industri UMJ Jakarta, November 2015.

Wakhid, M. (2014). Analisis Postur Kerja pada Aktivitas Pengangkutan Buah Kelapa Sawit dengan Menggunakan Metode Rapid Entire Body Assessment (REBA). Eprint Jurnal Udinus.

Wijaya, K. (2019). Identifikasi Risiko Ergonomi dengan Metode Nordic Body Map Terhadap Pekerja Konveksi Sablon Baju. Seminar Dan Konferensi Nasional IDEC, 1, ISSN 2579:6429. 